\title{
MODELO DE EQUAÇÕES DE DIFERENÇAS FINITAS APLICADO AO SISTEMA DE SAÚDE SUPLEMENTAR
}

\author{
FINITE DIFFERENCE EQUATION MODEL APPLIED TO THE SUPPLEMENTARY HEALTH SYSTEM \\ MODELO DE ECUACIONES DE DIFERENCIAS FINITAS APLICADO AL SISTEMA DE SALUD \\ SUPLEMENTARIA
}

\author{
Maurício Assuero Lima de Freitas ${ }^{1}$ \\ Alexandre Stamford da Silva ${ }^{2}$
}

Resumo Este estudo usa um modelo teórico e um modelo empírico, baseado em equações de diferenças finitas e equação de regressão linear, para analisar a tendência do mercado de seguro de saúde suplementar no Brasil. A resolução do modelo de equações de diferenças finitas gera três cenários possíveis para o mercado: no primeiro, haveria crescimento infinito dos recursos disponíveis no setor; no segundo, haveria estabilidade, dada a complementaridade da soma da fração da despesa com a fração do lucro, ambas calculadas sobre a receita: os recursos disponíveis no setor se situariam em torno do volume da contribuição inicial paga pelos indivíduos, estimada por regressão linear; finalmente, no terceiro cenário, o sistema seria levado à exaustão. Os resultados mostram que o sistema é sustentável no longo prazo.

Palavras-chave economia da saúde; saúde suplementar; equação de diferenças finitas.
Abstract This study uses a theoretical model and an empirical model based on finite difference and linear regression equations to analyze trends in the supplementary health insurance market in Brazil. The resolution of the finite difference equation model generates three possible scenarios for the market: in the first, there would be infinite growth of resources available in the industry; in the second, there would be stability, given the complementarity of the sum of the expense of the fraction with a fraction of the profit, both calculated on revenue: the resources available in the industry would be around the amount of the initial contribution paid by individuals, estimated based on linear regression; finally, in the third scenario, the system would be led to exhaustion. The results show that the system is sustainable over the long term.

Keywords health economics; health insurance; finite difference equation. 


\section{Introdução}

O Capítulo II do Título VIII da Constituição Federal do Brasil (Brasil, 1997) trata da saúde do cidadão, de um Sistema Único de Saúde (SUS) incumbido de ser descentralizado, igualitário e universal, e da participação da iniciativa privada no setor de saúde como forma suplementar. A regulamentação do SUS tem por base a lei n. 8.080/90, que, no seu artigo $4^{\circ}$, especifica que o SUS é composto pelo conjunto de instituições públicas (das três esferas de governo), incluindo empresas de controle de qualidade, pesquisa e produção de insumos, além de empresas de medicamentos e de equipamentos para a saúde (Brasil, 1990).

Este estudo 3 analisa o sistema de saúde suplementar por sua dimensão econômica. Dados da Pesquisa de Assistência Médico-Sanitária (Instituto Brasileiro de Geografia e Estatística, 2009), mostram que, aproximadamente, 33\% dos estabelecimentos de saúde existentes no Brasil, em 2009, pertenciam à iniciativa privada, que, dos 431.996 leitos disponíveis, detinha 279.104, ou seja, cerca de $64 \%$. Destaque-se, ainda, que, de um total de 1.104 .340 profissionais com curso superior que atuam no sistema de saúde, tem-se 636.017 (aproximadamente 57\%) médicos, dos quais 345.536 são vinculados ao setor suplementar de saúde. Acrescente-se, ainda, que: a) dos 23 milhões de internações em 2009, 15 milhões ocorreram no setor privado; b) dos 63.699 equipamentos de diagnósticos por imagem existentes no Brasil em 2009, 76\% pertencem à iniciativa privada (Instituto Brasileiro de Geografia e Estatística, 2009). Esta superioridade numérica do setor de saúde suplementar se observa também em outras variáveis, e como há investimentos privados (em infraestrutura, equipamentos etc.) é natural falar, como em qualquer atividade econômica, de retorno do capital investido, que é o principal motivo de decisão para uma empresa entrar ou não no mercado.

A regulamentação do setor de saúde suplementar teve início com a lei n. 9.656/98, que trata dos planos de assistência privada à saúde (promoveu adequação às empresas de seguro-saúde e impôs exigências legais para seu funcionamento), e culminou com a criação da Agência Nacional de Saúde Suplementar (ANS) por meio da lei n. 9.961/2000. Hoje a ANS dita as regras de funcionamento do setor privado com ações que vão desde a intervenção até a autorização do reajuste de preços. Consta na referida lei os critérios para entrada, funcionamento ou saída das empresas do setor, pelas quais se constata o impacto econômico da regulamentação neste mercado, que é o fato de uma operadora não poder sair do mercado sem que a sua carteira de clientes seja repassada a outra operadora. Portanto, a recomendação econômica de que uma empresa deve sair do mercado quando a curva de custo total médio está acima da linha de preços (Henderson e Quandt, 1992, p. 73; 
Pindyck e Rubenfield, 2006, p. 213) não é tão simples de ser aplicada no mercado de seguro-saúde diante da exigência legal de repasse da carteira, com o fito de proteger o consumidor. Por isso, as operadoras em dificuldades financeiras são passíveis de intervenção por parte da ANS, ou regime de administração especial, e não de pedido de concordata.

Uma das grandes preocupações do setor privado é a alta taxa de sinistralidade e o consequente comprometimento de suas receitas. A ANS (2010a) registra que, no período entre 2001 e 2009, aproximadamente 99\% das receitas obtidas pelas operadoras eram destinadas à cobertura de despesas administrativas (aluguel, mão de obra administrativa, impostos etc.) e despesas com assistência à saúde (consultas, exames laboratoriais, utilização de material descartável, medicamentos, procedimentos etc.). ${ }^{4}$ Observe-se que, enquanto o SUS conta com recursos do orçamento nas três esferas de governo para financiar os serviços de saúde, uma larga margem percentual do setor privado depende dos convênios firmados com as operadoras (empresas de seguro-saúde) e com o próprio governo (atendendo como conveniado ao SUS). Mais ou menos $95 \%$ do faturamento das empresas do setor suplementar (hospitais, laboratórios etc.) é oriundo dos convênios com as operadoras (Freitas, 2002, p. 43); os 5\% restantes são atendimentos de particulares (consultas e procedimentos médicos pagos diretamente pelo paciente).

Para abordar esse mercado, este estudo foi dividido em dois tópicos centrais. O primeiro discute a caracterização do problema e apresenta uma revisão de literatura. No segundo, dois modelos são apresentados: um teórico, baseado em equações de diferenças finitas, e outro empírico, calcado em regressão linear das receitas e dos gastos das operadoras contra o tempo.

Os coeficientes dessas regressões são utilizados como instrumento de explicação do modelo teórico. Ao final, são apontadas as consequências dos resultados obtidos.

\section{Caracterização do problema}

O enquadramento do sistema de saúde num determinado tipo de modelo está associado à forma de participação do Estado, ou seja, o que caracteriza cada sistema é a forma e a intensidade da participação do Estado. Dain e Janowitzer (2006, p. 18) destacam os modelos meritocrático ou de desempenho industrial (adotado por países como Alemanha, Áustria, França e Itália); o institucional-redistributivo (adotado por Dinamarca, Noruega, Suécia e Inglaterra); e o residual (adotado por Austrália, Suíça e Estados Unidos). Os autores afirmam que o sistema de saúde brasileiro nasceu num modelo meritocrático, mas transitou, parcial ou integralmente, pelos dois outros 
modelos. Nos Estados Unidos, por exemplo, o governo atende à população pelo medicare, que é um programa de seguro social destinado a pessoas acima de 65 anos, e pelo medicaid, destinado à população de baixa renda, sem seguro-saúde privado, de forma residual, visto que a população economicamente capaz usa o sistema privado (Dain e Janowitzer, 2006).

No Brasil, segundo dados da Pesquisa Nacional por Amostra de Domicílio (Instituto Brasileiro de Geografia e Estatística, 2009), 24,1 \% da população (45,7 milhões de pessoas) é atendida pelo setor de saúde suplementar por meio de convênios firmados com operadoras. Desse total, 35,5 milhões de pessoas, $18,7 \%$ da população total, compõem o mercado de seguros privados, e outros 10,2 milhões de pessoas, ou 5,4\% da população total, estão vinculados a planos públicos de assistência à saúde, que são as operadoras que trabalham na modalidade de autogestão. ${ }^{5}$ Portanto, $75,9 \%$ da população brasileira (142,8 milhões de pessoas) não possui planos privados de assistência à saúde, tornando-se potencial usuária do SUS.

Muito tem sido dito sobre o SUS. Fala-se da falência do sistema por questões que vão desde a dificuldade de acesso aos serviços de saúde às precárias condições de instalações (Bahia, 2005, p. 11), o que inclui a falta de médicos, de leitos em UTI etc. Discutem-se a descentralização (Ugá et al., 2003) e a equidade do sistema (Ugá e Santos, 2005), mas uma das maiores discussões na área da saúde pública é a fonte de financiamento do sistema (Barros, Piolla e Viana, 1996; Mansur, 2001)6 que, por um preceito constitucional inscrito no artigo 195 da Constituição Federal (Brasil, 1997), tem sua base no orçamento da seguridade social, constituído por contribuições de empregados (na forma de imposto sobre salários), de empregadores que são taxados sobre o lucro (Contribuição Social sobre o Lucro Líquido - CSLL) e sobre o faturamento (Programa de Integração Social - PIS; e Contribuição para Financiamento da Seguridade Social - Cofins) e dos prognósticos (arrecadação das apostas dos jogos administrados pela Caixa Econômica Federal). Piola e Biasoto-Júnior (2001, p. 219) aludem à instabilidade dessas fontes citando o cuidado dos constituintes de 1988 em assegurar, no mínimo, 30\% do orçamento da seguridade social para a saúde enquanto não fosse aprovada a lei de diretrizes orçamentárias. A Tabela 1 apresenta os valores, em bilhões de reais, dos componentes da seguridade social que formam o lastro financeiro da assistência à saúde, entre 2000 e 2009, no Brasil. 
Tabela 1

Receita dos componentes da Seguridade Social, em bilhões de reais, entre 2000 e 2009, destinados ao financiamento da saúde

\begin{tabular}{lcccccccccc}
\hline Item & 2000 & $\mathbf{2 0 0 1}$ & $\mathbf{2 0 0 2}$ & $\mathbf{2 0 0 3}$ & $\mathbf{2 0 0 4}$ & $\mathbf{2 0 0 5}$ & $\mathbf{2 0 0 6}$ & $\mathbf{2 0 0 7}$ & $\mathbf{2 0 0 8}$ & $\mathbf{2 0 0 9}$ \\
\hline CSLL & 7,5 & 7,2 & 9,9 & 12,7 & 15,7 & 20,2 & 21,8 & 26,8 & 34,0 & 34,9 \\
Cofins & 32,8 & 36,3 & 41,7 & 47,6 & 63,6 & 69,9 & 71,4 & 81,1 & 96,1 & 93,4 \\
PIS/Pasep & 4,9 & 5,3 & 6,2 & 8,2 & 9,6 & 10,7 & 11,4 & 12,4 & 14,8 & 14,9 \\
Prognósticos & 0,39 & 0,44 & 0,11 & 0,46 & 0,57 & 0,58 & 0,58 & 0,71 & 0,77 & 0,94 \\
Total & $\mathbf{4 5 , 6}$ & $\mathbf{4 9 , 2}$ & $\mathbf{5 7 , 9}$ & $\mathbf{6 9 , 0}$ & $\mathbf{8 9 , 5}$ & $\mathbf{1 0 1 , 4}$ & $\mathbf{1 0 5 , 2}$ & $\mathbf{1 2 1 , 0}$ & $\mathbf{1 4 5 , 7}$ & $\mathbf{1 4 4 , 1}$
\end{tabular}

Fonte: Brasil, 2010.

Nota: CSLL - Contribuição Social sobre o Lucro Líquido; PIS/Pasep - Programa de Integração Social/Programa de Formação do Patrimônio do Servidor Público; Cofins - Contribuição para Financiamento da Seguridade Social.

Conforme visto na Tabela 1 , a receita total da seguridade social aumentou $216 \%$, passando de $\mathrm{R} \$ 45,6$ bilhões para $\mathrm{R} \$ 144,1$ bilhões, no período considerado. Isto representa uma taxa média de crescimento de $13,9 \%$ ao ano. Note-se que a CSLL teve maior variação percentual, 365,3\%, crescendo, em média, $18,3 \%$ ao ano.

É importante discutir tais fontes, pela dimensão que o SUS tem e pelo preceito constitucional de que "a saúde é um direito do cidadão e um dever do Estado", que deixa implícito o acesso universal ao sistema de saúde, ou seja, o estado é obrigado a suprir recursos para atender a demanda em qualquer nível. Considerando que o Ministério da Saúde, em 2009, tinha orçamento da ordem de R\$ 66 bilhões $^{7}$ (superado apenas pelo Ministério da Previdência), a questão orçamentária passa a ser econômica.

Em relação ao setor de saúde suplementar, observa-se que há certa carência de discussão. Excetuando os congressos e encontros promovidos pelas associações de classe, não se encontram com facilidade trabalhos que tratem das questões econômicas do setor, muito embora algumas particularidades setoriais sejam analisadas de forma abrangente, como no caso da indústria de equipamentos médicos hospitalares (Pieroni, Reis e Souza, 2010; Cordeiro, 1980), ou, mais especificamente, da indústria de equipamentos médicos odontológicos (Manfredini e Botazzo, 2005). Sobre o mercado segurador de saúde, destaque-se que Bahia (2001, p. 325) faz uma abordagem generalista das tendências, com foco em uma análise qualitativa.

Outro fato que se observa nos estudos sobre o setor de saúde é a preferência por abordagens microeconômicas, tais como a discussão sobre a assimetria da informação (Lima, 2006); a demanda por serviços de saúde (Piolla e Vianna, 1995); ou métodos de construção de fronteira de eficiência (Marinho, 1998; Zucchi, Bittar, Haddad, 1998; Freitas, 2002), uma linha de pesquisa bastante explorada ao longo da década de 1990. As raras abordagens macroeconômicas tratam dos determinantes dos gastos privados com saúde (Andrade 
e Lisboa, 2002) ou analisam os gastos com saúde como fração do produto interno bruto (PIB) (Profuturo, 2008), e fazem uso, normalmente, de modelos econométricos. Tentativas de se avaliar a importância da saúde para o crescimento econômico, calcadas num modelo macroeconômico, podem ser vistas em Mankiw, Romer e Weil (1992) e Howitt (2005), mas a abordagem desses autores se respalda na importância do capital humano e defende que a boa saúde e a boa qualidade de vida, fato já abordado por Becker (1962), trazem implicações positivas para o crescimento econômico. A abordagem desse trabalho surge como uma ferramenta alternativa porque oferece um modelo matemático que pode ser testado, discutido, aprimorado. As equações de diferenças finitas permitem avaliar o comportamento das variáveis no tempo discreto, mas servem como um preâmbulo para modelos dinâmicos no tempo contínuo.

Folland, Goodman e Stano (2008, p. 32) defendem a importância de se estudar economia da saúde lembrando que são formuladas políticas públicas para o setor de saúde, há impacto da saúde sobre o crescimento econômico e existem inúmeros aspectos da saúde envolvendo variáveis econômicas (produção, custos, inflação no setor de saúde, alocação ótima de recursos etc.). Por isso, é necessário olhar para o sistema de saúde como um setor de produção que usa capital, trabalho e tecnologia para produzir pessoas sadias e destinar atenção a um setor que investe capital esperando retorno financeiro como em qualquer outra atividade econômica. No entanto, cabe lembrar que um estudo econômico do setor de saúde esbarra muitas vezes nas suas particularidades, que são diversas das do setor de produção de bens de consumo. Dentre elas, pode-se citar a questão da estrutura do setor, que dificulta sua classificação como oligopólio (hospitais especializados) ou concorrência perfeita (laboratórios de análises clínicas). Se o mercado é competitivo, então os hospitais privados igualam o preço ao custo marginal para determinar o volume ótimo de produção? Se um hospital especializado em cardiologia, por exemplo, define que sua quantidade ótima de atendimentos diária é $x$ pacientes, então o que fazer com o $(x+1)$-ésimo paciente que chegar com risco de morte? Ele deve ser atendido ou encaminhado a outra unidade? Um médico que atende diversos pacientes num consultório particular tem poder de mercado?

Estas questões são muito apropriadas para o setor de saúde privado. Daí decorre a importância de se trazer ao debate questões relacionadas, por exemplo, com a fonte de financiamento desse setor, porque, se no setor público tais fontes estão bem estabelecidas, a base de financiamento do setor privado é o convênio (tanto com as operadoras quanto com o governo) 8 e o pagamento de particulares.

Assim, como a sustentabilidade do setor de saúde suplementar depende das operadoras, ao observar o período entre dezembro de 1999 e março de 
2010, nota-se que há redução na quantidade de empresas, e surge a preocupação com o futuro desse mercado. O Gráfico 1 mostra a quantidade de empresas registradas na ANS entre dezembro de 1999 e março de 2010.

\section{Gráfico 1}

Quantidade de empresas de seguro saúde entre 1999 e 2010

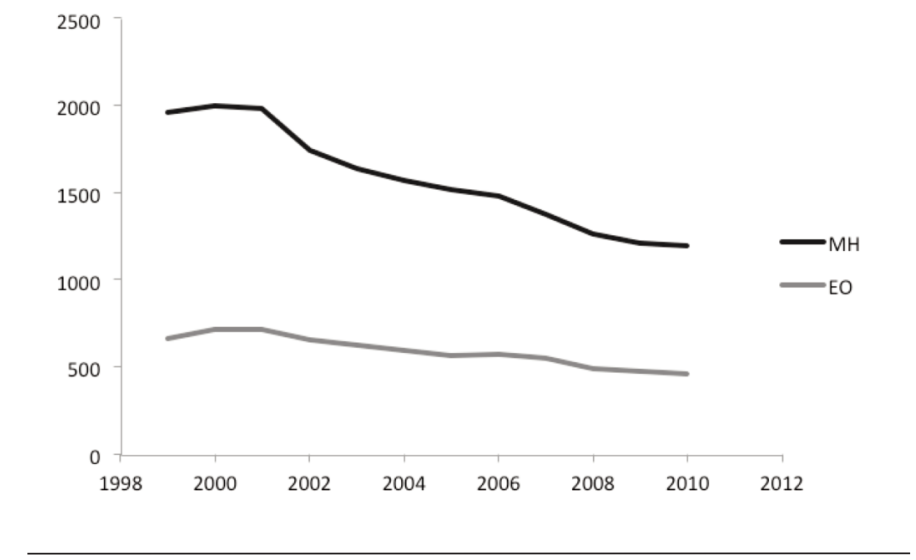

Fonte: Elaboração própria com base em dados da ANS.

Nota: MH - Médico-hospitalares; EO - Exclusicamente odontológicas.

A quantidade de empresas do tipo $\mathrm{MH}$ (médico-hospitalares) e do tipo EO (exclusivamente odontológicas) diminuiu 39\% e $31 \%$, respectivamente, no período referido. Há uma justificativa puramente mercadológica para esse fato: muitas empresas do setor tiveram dificuldades em cumprir suas obrigações perante os prestadores de serviços (médicos, hospitais, laboratórios etc.) e sofreram intervenção por parte da ANS, tendo sua carteira de clientes incorporada por outras empresas. Entretanto, mesmo contemplando $25 \%$ da população, como já referido, a importância do setor de saúde suplementar, no Brasil, pode ser resumida nos seguintes dados (Instituto Brasileiro de Geografia e Estatística, 2009):

- Dos 74.776 estabelecimentos de saúde existentes no Brasil, 24.523 (33\%) são privados. Desse total, 4.036 com internação (o setor público detinha 2.839 estabelecimentos com internação);

- Dos 431.996 leitos disponíveis, 279.104 (64\%) estão na iniciativa privada;

- Dos 63.699 equipamentos existentes de diagnóstico através de imagens, $48.484(76 \%)$ ) pertencem ao setor de saúde suplementar;

- Dos 44.373 equipamentos de infraestrutura, 31.446 (71\%) pertencem ao setor de saúde suplementar; 
- Dos 22.761 equipamentos de métodos óticos, 17.967 (79\%) pertencem ao setor de saúde suplementar.

Ainda de acordo com o IBGE (2009), o sistema de saúde brasileiro contava, em 2009, com 526.620 equipamentos médico-hospitalares, ${ }^{9}$ dos quais 356.258 , aproximadamente $67 \%$, pertencentes à esfera privada (isso representa cerca de 17 equipamentos para cada 10 mil habitantes). 10 Adicionalmente, em 2007 o Datasus 11 registrou 2,57 consultas por habitante no Brasil no setor público, enquanto no mesmo ano foram realizadas 5,3 consultas por beneficiários de planos de assistência à saúde privados (Agência Nacional de Saúde, 2010a).

Os números apresentados acima refutam a premissa de Arrow (1962), que introduziu a incerteza no setor de saúde como uma variável existente tanto no lado da demanda quanto no lado da oferta, e esta hipótese tem passado sem maiores críticas. Do ponto de vista da oferta, a incerteza não se justifica porque a iniciativa privada não investiria em tecnologia, infraestrutura etc. se não considerasse que incerto é o momento no qual a doença acomete o indivíduo. Por outro lado, o estoque de saúde do indivíduo tende a se reduzir com o tempo, logo, pessoas mais velhas são mais propensas a adoecer e precisarão de serviços de saúde. Estes argumentos justificam os investimentos no setor de saúde suplementar e tornam o aspecto da incerteza na oferta de serviços de saúde menos relevante. 12

As dificuldades do setor suplementar estão fortemente atreladas às questões econômicas e judiciais. O nascedouro das querelas judiciais é a interpretação do contrato em face do direito à saúde, segundo reza a Constituição Federal (Brasil, 1997). Em muitas situações, a operadora alega doença preexistente para não autorizar um procedimento ou pretende escolher o tipo de atendimento a ser prestado, mas, pelo entendimento da Terceira Turma do Tribunal Superior de Justiça, “o plano de saúde pode estabelecer quais doenças estão sendo cobertas, mas não que tipo de tratamento está alcançado para a respectiva cura" (Tribunal Superior de Justiça, 2007). Como resultado, devido à assimetria da informação existente no setor, não é possível determinar se a prescrição do médico beneficia o paciente, o hospital ou, por extensão, ele próprio. Além disso, a formalização de um contrato de seguro-saúde entre usuário e operadora se baseia na fé de um questionário preenchido pelo indivíduo sobre o seu estado de saúde naquele instante. $\mathrm{O}$ indivíduo pode não declarar doenças preexistentes por uma questão de má-fé ou por desconhecimento e, com isso, a operadora incorre numa seleção adversa.

Outro aspecto polêmico no setor é fruto da resolução n. 1806/2006 do Conselho Federal de Medicina (CFM) que diz, no seu artigo primeiro: “É permitido ao médico limitar ou suspender procedimentos e tratamentos que prolonguem a vida do doente em fase terminal, de enfermidade grave e 
incurável, respeitada a vontade da pessoa ou de seu representante legal" (Conselho Federal de Medicina, 2006).

A resolução autoriza a prática da ortotanásia, e as operadoras teriam benefício direto com essa prática. Todavia, a Associação Brasileira de Medicina de Grupo (Abramge) 13 defende outros mecanismos de contenção de gastos. Um dos caminhos para atenuar os gastos é implantar dispositivos que reduzam a informação assimétrica e o risco de seleção adversa. Esse esforço parecerá pouco se o custo marginal de utilização do seguro-saúde continuar sendo zero para o usuário.

Do ponto de vista econômico, o setor precisa de recursos para pagar os procedimentos realizados pelos prestadores de serviços (hospitais, clínicas, médicos, laboratórios etc.), e esses recursos são oriundos das operadoras. Estas dependem da base de vidas (o número de associados ou de usuários que possuem), mas não necessariamente do aumento da população, e o aumento da base de vidas depende do aumento do emprego, visto que 24 milhões dos beneficiários em março de 2010 (Agência Nacional de Saúde, 2010a) estavam vinculados a planos empresarias, e da renda do indivíduo, dado que o aumento de renda enseja a contratação de um seguro-saúde individual. ${ }^{14}$

As operadoras captam recursos para cobrir a sinistralidade, as despesas administrativas e remunerar o capital, mas, de acordo com a Tabela 2 (que mostra, por tipo de operadora, o índice de sinistralidade no Brasil no período entre 2003 e o primeiro trimestre de 2010), é expressivo o grau de comprometimento da receita com despesas com assistência à saúde, e, quando se adicionam as despesas administrativas, a margem de lucro fica bastante comprometida.

Tabela 2

\begin{tabular}{|c|c|c|c|c|c|c|c|c|}
\hline Modalidade da operadora & 2003 & 2004 & 2005 & 2006 & 2007 & 2008 & 2009 & $2010(*)$ \\
\hline Operadoras médico-hospitalares & 81,3 & 81,5 & 81,4 & 79,7 & 80,5 & 80,4 & 83,0 & 78,4 \\
\hline Autogestão & 82,7 & 90,9 & 87,9 & 83,0 & 87,6 & 91,9 & 94,5 & 82,1 \\
\hline Cooperativa médica & 83,6 & 83,0 & 81,8 & 80,7 & 79,6 & 81,3 & 82,4 & 76,4 \\
\hline Filantropia & 73,3 & 77,1 & 73,5 & 75,6 & 53,5 & 53,0 & 82,7 & 72,0 \\
\hline Medicina de grupo & 75,9 & 75,2 & 75,7 & 75,9 & 77,0 & 77,4 & 79,0 & 76,0 \\
\hline Seguradora especializada em saúde & 86,2 & 87,2 & 90,0 & 84,0 & 89,7 & 81,5 & 83,6 & 84,0 \\
\hline Exclusivamente odontológicas & 55,2 & 51,0 & 49,3 & 46,2 & 47,9 & 47,7 & 48,7 & 36,2 \\
\hline Cooperativa odontológica & 76,3 & 66,6 & 65,7 & 63,1 & 64,8 & 65,1 & 63,8 & 56,5 \\
\hline Odontologia de grupo & 44,9 & 42,4 & 41,1 & 39,5 & 40,7 & 39,9 & 42,0 & 28,0 \\
\hline Total & 80,9 & 80,9 & 80,8 & 79,0 & 79,9 & 79,7 & 82,3 & 77,5 \\
\hline
\end{tabular}

Fonte: Agência Nacional de Saúde, 2010b.

$\left({ }^{*}\right)$ Primeiro trimestre de 2010, e passível de ajustes. 
Outro aspecto crucial com o qual as operadoras se defrontam é decorrente do avanço tecnológico, pois "A crescente disponibilidade das mais recentes tecnologias e de tratamentos de alto custo acrescentou uma pressão ascendente sobre os custos da assistência à saúde" (Folland, Goodman e Stano, 2008, p. 48).

A tecnologia do setor de saúde permite realizar diagnósticos mais rápidos e mais eficientes, e o tempo de recuperação de alguns procedimentos médicos, atualmente, é bem menor do que num passado não tão distante. Por um lado, isso traz contribuições positivas para o sistema econômico, pois o indivíduo volta mais rápido para a produção e, por outro lado, reduzem-se os gastos decorrentes de internações (hotelaria, uso de descartáveis, medicamentos etc.). Entretanto, as tecnologias recentes também oneram os convênios. Freitas (2009, p. 67) apresenta o caso de um procedimento médico denominado embolização percutânea que pode ser realizado mediante uma cirurgia de crânio aberto ao preço15 de R 8 mil ou, usando tecnologia recente, 16 ao preço de $\mathrm{R} \$ 78 \mathrm{mil}$ (quando o material é adquirido diretamente do fabricante) ou de até $\mathrm{R} \$ 163 \mathrm{mil}$ (quando o material é adquirido do distribuidor ou do próprio hospital). A realização de dez cirurgias mensais já compromete o desempenho financeiro de qualquer operadora que tenta equilibrar seu fluxo de caixa por meio de glosas, da criação de pacotes para determinados procedimentos 17 ou de autorização prévia para procedimentos de alta complexidade. Observe-se que o preço do procedimento é fixado pela operadora, ou seja, o prestador (hospital, médico etc.) tem um parâmetro de receita, mas e se houver complicações durante o procedimento e esse preço não for suficiente para cobrir custos e gerar lucro?

Essa questão remete para a constatação de que falta um modelo de precificação para o setor de saúde. É preciso separar o valor da vida do valor do procedimento médico. Aparentemente, as tecnologias recentes são precificadas com base no valor da vida. Quando um indivíduo paga, mensalmente, um seguro-saúde, do ponto de vista econômico ele está formando uma poupança visando futuras utilizações. Se o valor mensal exigido for $R$ reais, então, após $n$ contribuições, o saldo da poupança formada seria dado por

$$
S=R \times\left[\frac{(1+i)^{n+1}-1}{i}-1\right]
$$

Onde $i$ é uma taxa mensal de juros vigente no mercado. Uma pessoa que pagou mensalmente, 18 em média, $\mathrm{R} \$ 150,00$, teria, após cem meses de contribuições, uma poupança de $\mathrm{R} \$ 25.827,93$ para uma taxa de juros de $1 \%$ ao mês. Esta poupança não é suficiente para cobrir a embolização percutânea citada. Assim, a empresa de seguro-saúde vai utilizar a poupança de outros 
contribuintes para arcar com tal procedimento. ${ }^{19}$ É preciso avaliar o impacto que este fato, aliado ao elevado índice de sinistralidade, gera no desempenho financeiro das operadoras e, por conseguinte, na disponibilidade de recursos para financiar a atividade dos prestadores.

\section{Modelos teórico e empírico}

Nesta seção serão discutidos dois modelos para o setor de saúde suplementar. Inicialmente, discute-se um modelo teórico que utiliza equações de diferenças finitas. No segundo momento, utiliza-se um modelo empírico obtido mediante regressão linear, considerando o resultado financeiro (lucro) das operadoras contra o tempo. O modelo de regressão é importante porque seu objetivo é verificar, a partir da determinação dos parâmetros, qual cenário justifica o modelo teórico.

A receita das operadoras é oriunda dos contratos firmados com indivíduos e empresas. O preço é fixado de acordo com a faixa etária do beneficiário. Desprezando a receita não operacional obtida com aplicações financeiras ou desimobilização, por exemplo, uma via de crescimento da receita das operadoras seria o aumento da base de vidas, isto é, a formalização de novos contratos. Seria possível computar o aumento de receita pelo aumento dos preços, desde que este superasse a inflação do setor, todavia este trabalho não considera os efeitos inflacionários e descarta crescimento de receita por esta via. Os valores utilizados no modelo de regressão são nominais porque a variável explicativa é o tempo. Isso está sendo considerado para que haja consonância entre ambos os modelos.

A receita obtida pelas operadoras é o lastro para o pagamento das despesas administrativas, das despesas com assistência à saúde (custos com a sinistralidade) e da remuneração do capital. A operadora, nos novos contratos, impõe um período de carência para determinados procedimentos. Pode-se entender que, do ponto de vista econômico, essa carência gera recursos para criar disponibilidade financeira para a operadora. O lucro ou resultado disponível, em cada instante de tempo, $t=1,2,3, \ldots$, é determinado por

$$
R_{\mathrm{t}}=C_{\mathrm{t}}-U_{\mathrm{t}}
$$

Onde $U_{\mathrm{t}}$ é o volume de gastos (despesas) das operadoras e $C_{\mathrm{t}}$ representa a contribuição pecuniária do beneficiário. Formalmente, a receita da operadora é igual às contribuições das contraprestações dos usuários. As obrigações pecuniárias do indivíduo perante a operadora são antecipadas, isto é, o indivíduo só pode utilizar os serviços, salvo determinação legal, após o pagamento da contraprestação. 
A despesa, em qualquer tempo, é uma variável controlada pela operadora 20 e pode ser vista como uma fração do que foi contribuído no período anterior, ou seja, matematicamente pode-se escrever $U_{\mathrm{t}}=\alpha C_{\mathrm{t}-1}$. Note que pode ocorrer $\alpha>1$, isto é, o volume de despesas da operadora pode ser superior ao volume arrecadado no período anterior, levando a operadora a cobrir despesas com parte dos recursos recebidos na data $t$. Também é verdadeiro que a contribuição de um período, $C_{\mathrm{t}}$, pode ser maior, igual ou menor do que $C_{\mathrm{t}-1}$, fato que pode depender ou não da formalização de novos contratos. Assim, sem perda de generalidade, pode-se escrever $R_{\mathrm{t}}=\beta C_{\mathrm{t}}$, onde $0<\beta<1$. Substituindo as expressões de $U_{\mathrm{t}}$ e $R_{\mathrm{t}}$, aqui determinadas, na equação (1), obtém-se

$$
C_{t}=\left(\frac{\alpha}{1-\beta}\right) C_{t-1}
$$

que é uma equação de diferença finita. Braga, Kannebley Júnior e Orellano (2003, p. 447) tratam as equações de diferenças finitas de $1^{a}$ ordem homogêneas como sendo aquelas escritas na forma $y_{\mathrm{t}+1}-\mathrm{a} y_{\mathrm{t}}=0$ cuja solução se obtém por recorrência, a partir de um valor inicial, e é dada por $y_{\mathrm{t}+1}=\mathrm{a}^{\mathrm{t}+1} y_{0}$. A equação (2) tem exatamente este formato, e sua solução é dada por:

$$
C_{t}=\left(\frac{\alpha}{1-\beta}\right)^{t} C_{t-1}
$$

Onde $C_{0}$ é dado. O comportamento dessa solução depende do coeficiente $\frac{\alpha}{1-\beta}$. Se ocorrer $\alpha=1-\beta$, então as receitas (contribuições) são estáveis. O sistema fica, infinitamente, num estado de inércia, repartindo $C_{0}$ entre as operadoras. Este cenário favorece a aquisição e/ou fusão entre as operadoras porque a saída de uma operadora do mercado aumentaria a participação de outra na distribuição de $C_{0}$. Por um lado, as aquisições e fusões que ocorrem no setor podem ser justificadas como uma forma de ganhar uma fatia maior no mercado. ${ }^{21}$ Se $\alpha>1-\beta \Rightarrow \alpha+\beta>1$, o mercado é sustentável no longo prazo. Significa que a base de vidas do mercado cresceu, e economicamente isso pode estar associado ao aumento da empregabilidade e/ou da renda. Por outro lado, os gastos com serviços de saúde e gastos administrativos são controlados endogenamente pela operadora por meio de ações já referidas (glosas, autorizações, limitação de dias de internação, escolha de material descartável etc.). Assim, mediante uma adequada política de controle de gastos associada com uma ação voltada para o crescimento da base de vidas, o setor poderá desfrutar de recursos infinitamente. Caso ocorra $\alpha+\beta<1$, não haverá recursos disponíveis para custear o sistema de saúde suplementar e, neste caso, os beneficiários do sistema de saúde suplementar sobrecarregariam o SUS. 22 
A resolução do modelo começa com a aplicação de logaritmo na equação (3), para se obter um modelo de regressão linear dado por:

$$
\ln C_{\mathrm{t}}=\ln C_{\mathrm{t}-1}+\ln \left(\frac{\alpha}{1-\beta}\right) t=K_{0}+K_{1} t
$$

onde,

$$
K_{0}=\ln C_{\mathrm{t}-1}
$$

$\mathrm{e}$

$$
K_{1}=\ln \left(\frac{\alpha}{1-\beta}\right)
$$

Determinando os valores de $K_{0}, K_{1}$ no modelo de regressão linear dado por (4), obtém-se com facilidade os parâmetros da relação $\frac{\alpha}{1-\beta}$, da equação (3), que mostra o tipo de cenário do mercado. A ANS disponibiliza informações referentes à receita, despesas com assistência à saúde e despesas administrativas das operadoras. Este trabalho utiliza tais variáveis no período entre 2001 e 2009, inclusive, para estimar o modelo de regressão linear. Acrescente-se que o fato de se ter uma pequena quantidade de observações não invalida o modelo. A micronumerosidade já foi tratada na literatura e comparada à multicolinearidade, 23 e isso faz sentido quando o número de observações está próximo do número de variáveis, o que não é o caso do modelo aqui utilizado. Ressaltando que o modelo empírico não será usado para projeções, desprezam-se questões relativas a heterocedasticidade e autocorrelação, visto que, mesmo em presença de ambas, os parâmetros da regressão são não tendenciosos. Assim, opta-se pela significância dos parâmetros.

A Tabela 3 mostra os resultados das regressões especificadas para receita e despesas, respectivamente, contra o tempo.

\begin{tabular}{|c|c|c|c|c|c|c|c|c|}
\hline \multirow[b]{2}{*}{ Variável } & \multicolumn{4}{|c|}{ Contribuições } & \multicolumn{4}{|c|}{ Lucro } \\
\hline & Coeficientes & Erro padrão & Estatística $t$ & p-valor & Coeficientes & Erro padrão & Estatística t & $\mathrm{p}$-valor \\
\hline Constante & 23,6718 & 0,0236 & 1004,59 & 0,0000 & 20,0086 & 0,5787 & 34,5756 & 0,0000 \\
\hline \multirow[t]{2}{*}{$\mathrm{T}$} & 0,1384 & 0,0042 & 33,06 & 0,0000 & 0,0699 & 0,1028 & 0,6800 & 0,5184 \\
\hline & \multicolumn{4}{|c|}{$R^{2}=0,9936$} & \multicolumn{4}{|c|}{$R^{2}=0,2489$} \\
\hline
\end{tabular}

Tabela 3

Parâmetros da regressão de receita e despesa contra o tempo

Fonte: Os autores. 
Como se observa na Tabela 3, os coeficientes referentes às contribuições são estatisticamente significativos ao nível de significância de 5\%. Da equação (5), tem-se que $C_{\mathrm{t}-1}=e^{23,6718}$ (aproximadamente $\mathrm{R} \$ 19$ bilhões), e da equação (6), segue que

$$
\frac{\alpha}{1-\beta}=e^{0,1384}=1,1485
$$

Com isso, deduz-se que o sistema é sustentável no longo prazo.

Substituindo a equação (3) em $R_{\mathrm{t}}=\beta C_{\mathrm{t}}$ obtém-se $R_{\mathrm{t}}=\beta\left(\frac{\alpha}{1-\beta}\right)^{t} C_{\mathrm{t}-1}$. Aplicando logaritmo a ambos os lados, tem-se

$$
\ln R_{\mathrm{t}}=\ln \beta C_{\mathrm{t}-1}+\ln \left(\frac{\alpha}{1-\beta}\right) t=K_{2}+K_{1} t
$$

Onde

$$
K_{2}=\ln \beta C_{\mathrm{t}-1}
$$

Propositadamente, manteve-se a equação (8) com a mesma inclinação da equação (4), seguindo a intuição de que lucro e contribuição pudessem ser afetados da mesma maneira, ao longo do tempo. O lado direito da Tabela 3 mostra que o coeficiente angular passa a ser não significativo quando a variável dependente é o lucro, numa clara sugestão de que outras variáveis, além do tempo, afetam a lucratividade. Decorre da equação (7) que $\beta C_{\mathrm{t}-1}=e^{20,0086} \Rightarrow \beta=e^{(20,0086-23,6718)} \cong 0,0257$. Daí, a lucratividade das operadoras do setor de saúde suplementar é, aproximadamente, de 2,57\%. Da equação (7), tem-se que $\alpha=(1-\beta) e^{0,1384}=1,1190$.

Os resultados mostram que o setor apresenta baixa lucratividade e utiliza recursos das contribuições atuais para cobrir as despesas, uma vez que que compromete uma parcela maior do que arrecada no período anterior. Noutras palavras: o sistema de saúde suplementar estaria mais confortável financeiramente se $0<\alpha<1$.

A sustentabilidade do setor, baseada na receita das operadoras, pode ser vista sob alguns aspectos, entre os quais a questão da precificação. Como se sabe, a operadora fixa preços por faixa etária e de acordo com os contratos firmados; quando ocorre mudança de faixa, aplica-se um incremento percentual sobre o valor da prestação. O preço pago por procedimentos é o mesmo, independente da faixa etária. Por exemplo, uma tomografia computadorizada tem o mesmo valor quer seja feita numa criança, quer num adulto; um médico recebe da operadora o mesmo valor por uma consulta quer tenha atendido uma pessoa de cinco ou de 50 anos. Assim, quando a operadora impõe um percentual de reajuste por mudança de faixa etária, busca aumentar a margem de lucro. Isto pode ser verificado caso a sinistra- 
lidade seja fornecida por faixa etária. No entanto, esta informação não está disponível na ANS.

\section{Consequências}

O sistema de saúde suplementar, no curto prazo, sobrevive economicamente dos conflitos de interesses entre as entidades que o compõem. Os preços dos procedimentos são determinados pelas operadoras e, com isso, os prestadores só podem aumentar suas receitas mediante o aumento de atendimentos. Surge, aqui, o sentimento natural de que a permanência do indivíduo no sistema de saúde deve ser estendida para que haja agregação de lucros.

As inovações tecnológicas no setor trazem não apenas diagnósticos rápidos, mas também uma necessidade de aumentar a quantidade de atendimentos para pagar investimentos realizados, principalmente na aquisição de equipamentos de última geração. Em outras palavras: a necessidade do retorno financeiro dos investimentos realizados pelos prestadores surge como uma decorrência da atualização tecnológica do setor e, com isso, o prestador passa a depender de indicações e encaminhamentos médicos, fato concretizado pela formalização de parcerias entre essas partes, no seguinte sentido: os médicos fazem atendimentos, exames e procedimentos dentro dos hospitais, ou seja, atraem o paciente para o hospital, gerando demanda pelos serviços, e, em contrapartida, recebem uma fração da receita decorrente dos procedimentos que realizaram.

Quando, por exemplo, um hospital adquire um equipamento com tecnologia recente, a concorrência reage investindo também para não perder mercado. Por conseguinte, as operadoras são penalizadas pelo incremento das despesas. É esperado ocorrer aumento na quantidade de sinistros do setor com consequente impacto para as despesas das operadoras. Resta à operadora implantar mecanismos de defesa, e estes surgem através da constituição de setores específicos, denominados de auditoria médica, em que se avalia a solicitação de procedimentos de alta complexidade, de internações e cirurgias. A operadora equilibra seu fluxo de caixa controlando as autorizações para tais procedimentos.

Outra questão crucial para o setor é que o reajuste dos preços é uma variável exógena, controlada pela ANS, e pode provocar migração de usuários entre planos, 24 visto que compromete a renda. A fixação dos preços é uma prerrogativa da ciência atuarial, no entanto os percentuais desejados pelas operadoras estão, geralmente, acima daqueles autorizados pela ANS. Além disso, a ANS tinha por norma divulgar um reajuste de preços linear, ou seja, tratava de igual forma as operadoras de alto custo e as operadoras de baixo custo. Com tantas dificuldades, questiona-se a razão pela qual o capitalista 
permanece no setor. Uma possível resposta, que justifica inclusive a sustentabilidade do sistema, está na composição dos planos comercializados. Em setembro de 2012, a ANS registrava 48,660 milhões de beneficiários de seguro-saúde, dos quais 30,764 milhões $(63,22 \%)$ estão vinculados aos planos coletivos empresariais; 6,637 milhões (13,63\%) estão vinculados aos planos coletivos por adesão e 9,964 milhões $(20,47 \%)$ são planos individuais. Os planos coletivos não estão submetidos às mesmas regras contratuais que os planos individuais, ou seja, num plano coletivo a operadora pode cancelar unilateralmente o contrato, o aumento dos preços não se subordina à aprovação da ANS, dentre outras prerrogativas. Entre dezembro de 2000 e setembro de 2012, a quantidade de beneficiários de planos coletivos passou de 11,321 milhões para 37,433 milhões, ou seja, um crescimento de $213 \%$, enquanto, no mesmo período, a quantidade de beneficiários dos planos individuais passou de 5,658 milhões para 9,963 milhões, ou seja, um crescimento de $76 \%$. A ANS disponibiliza uma relação de planos que estão proibidos de firmar novos contratos, movida, por exemplo, pelo índice de reclamações dos clientes. Todavia, a acomodação das operadoras em não resolver as queixas indica a opção de reduzir a comercialização de tais planos individuais. É preciso avaliar as implicações que isso trará para o sistema de saúde, para a economia e para o cidadão.

O setor de saúde suplementar necessita de políticas que discutam a fonte de financiamento, a precificação dos procedimentos, o impacto das decisões judiciais, a assimetria de informação, entre outras, inclusive o papel dos demais componentes do sistema, como a indústria de equipamentos (que fornece a tecnologia dos diagnósticos e dos procedimentos), a indústria farmacêutica (que fornece a tecnologia da droga e para a qual é melhor manter o usuário no sistema de saúde do que curá-lo) e o governo (cujas decisões podem afetar o mercado intensamente), visto que os interesses de cada um afetam diretamente o mercado segurador de saúde.

\section{Conclusão}

Aparentemente, não se explica o motivo de se ter capital investido em empresas de seguro-saúde, dado que aproximadamente $99 \%$ da receita das operadoras está comprometida com as despesas referentes à assistência à saúde e despesas administrativas. Isso pode ser um questionamento à racionalidade do capitalista, no entanto, de acordo com os modelos aqui apresentados, o sistema de saúde suplementar é sustentável no longo prazo.

Este trabalho mostrou, num primeiro momento, um modelo teórico baseado em equações de diferenças finitas para avaliar os resultados financeiros do mercado de seguro-saúde privado, e foram apresentados três cenários 
possíveis relacionados com o comportamento da solução da equação dada por (3). Num dos cenários, $\alpha+\beta=1$, o modelo gira em torno de um valor inicial a ser repartido entre as operadoras, indefinidamente. Se $\alpha+\beta<1$, então não há sustentabilidade no longo prazo, o que traria consequências graves para o sistema de saúde brasileiro, visto que o atendimento da população seria feito pelo setor público. O modelo empírico, baseado em regressão linear tendo o tempo como variável explicativa, mostrou o terceiro cenário no qual $\alpha+\beta>1$, ou seja, as contribuições crescerão com o tempo, fato que justifica a permanência das operadoras no mercado. $O$ principal argumento para a sustentabilidade do mercado está na opção pela comercialização de planos coletivos, em detrimento dos planos individuais, todavia esta opção traz consequências econômicas e sociais.

Observe-se que a utilização do tempo como variável explicativa negligencia outras questões importantes como a taxa de juros, a inflação do setor, a precificação da tecnologia, o comportamento da base de vidas, entre outras, no entanto o modelo apresentado atendeu às necessidades do estudo, que era discutir a sustentabilidade do setor suplementar de saúde à luz das receitas e despesas divulgadas pelas operadoras. Atestar a veracidade de tais informações não está nos planos deste texto.

Algumas empresas saíram do mercado ao longo do tempo, conforme visto no Gráfico 1, mas pelos resultados dos modelos deve-se atribuir tais decisões a questões administrativas e não econômicas ou mercadológicas. Como se sabe, uma empresa de seguro-saúde não é suscetível a um pedido de falência ou concordata, mas de intervenção por parte da ANS, cujo regime de administração especial busca potenciais compradores para a carteira de clientes. Nota-se que isto representa algum nível de risco para a empresa adquirente, pois uma carteira problemática (com elevadas taxas de sinistralidade, com passivo expressivo em aberto etc.) pode contaminar seu desempenho. Ainda assim, não são estranhas as fusões e incorporações no setor, no entanto há de se cuidar para que o mercado não fique concentrado.

Finalmente, o trabalho apresenta algumas questões cruciais para o sistema de saúde suplementar, como a falta de poupança, a falta de modelo de precificação dos procedimentos, o impacto ou mesmo a precificação da tecnologia etc., mas deixa tais questões para análises futuras. 
Resumen Este estudio usa un modelo teórico y un modelo empírico, basado en ecuaciones de diferencias finitas y ecuación de regresión lineal, para analizar la tendencia del mercado de seguro de salud suplementaria en Brasil. La resolución del modelo de ecuaciones de diferencias finitas genera tres escenarios posibles para el mercado: en el primero, habría un crecimiento infinito de los recursos disponibles en el sector; en el segundo, habría estabilidad, dada la complementariedad de la suma de la fracción del gasto con la fracción de las utilidades, ambas calculadas sobre los ingresos: los recursos disponibles en el sector se situarían en torno del volumen de la contribución inicial pagada por los individuos, estimada por regresión lineal; finalmente, en el tercer escenario, el sistema sería conducido al agotamiento. Los resultados muestran que el sistema es sustentable en el largo plazo.

Palabras clave economía de la salud; salud suplementaria; ecuación de diferencias finitas.

\section{Notas}

1 Universidade Federal de Pernambuco, Departamento de Ciências Contábeis e Atuariais, Recife, Pernambuco, Brasil.

<massuero@ig.com.br>

Correspondência: Rua Itapetininga, 75, Curado, CEP 50790-410, Recife, Pernambuco, Brasil.

2 Universidade Federal de Pernambuco, Departamento de Economia, Recife, Pernambuco, Brasil.

<alexandre@stamford.pro.br>

3 Trata-se de uma modelagem para o sistema de saúde suplementar e não teve apoio financeiro de nenhuma instituição. Os autores têm interesse de pesquisa na área de economia da saúde; o segundo foi orientador do primeiro no mestrado e no doutorado, com temas relacionados à economia da saúde. Este artigo, todavia, surgiu de um comentário constante na tese sobre os trabalhos voltados para o sistema de saúde suplementar. O artigo não é, propriamente, um resultado da tese, mas foi um dos seus argumentos.

4 De acordo com a resolução normativa n. 173, de 10 de julho de 2008, da ANS, as operadoras são obrigadas a fornecer, periodicamente, informações econômico-financeiras (documento de informações periódicas das operadoras de planos de assistência à saúde DIOPS/ANS) à ANS.

5 Empresas que possuem sua própria rede de atendimento para seus funcionários e dependentes.

6 O problema da fonte de financiamento está relacionado com os aspectos da descentralização e da equidade do sistema.

7 A dotação orçamentária dos ministérios está disponível em www.planejamento. gov.br (consultado em 1 jul. 2010).

8 A formalização do convênio entre o governo e a iniciativa privada está expressa nos artigos 24 e 25 . 
${ }^{9}$ Equipamentos de diagnóstico por imagem, de manutenção à vida, métodos gráficos e óticos, terapia por radiação e de infraestrutura.

10 No setor privado, a velocidade de aquisição ou reposição de equipamentos e de investimentos em novas unidades é maior do que no setor público, visto que a iniciativa privada não se submete aos processos de licitação.

11 Para maiores informações, consultar http://datasus.saude.gov.br/informacoes-desaude/business-intelligence-bi/informacoes-de-mortalidade.

12 Todo processo produtivo tem um grau de incerteza envolvido. O que se pretende dizer é que, independente da incerteza, o setor privado investe e não investiria se não tivesse certeza de retorno financeiro. O que se defende aqui é a racionalidade do empresário de saúde do setor privado.

13 Nota do presidente da Abramge, divulgada na imprensa, disponível em http://gl.globo.com/jornal-da-globo/noticia/2010/08/abrange-esclarece-que-nao-defendeortotanasia.html.

14 É possível que o aumento da renda tenha um efeito mínimo na substitutibilidade de planos, ou seja, se a renda do indivíduo aumenta, não há indicativo de migração para outros planos nem para outras classes de atendimento dentro do próprio plano.

15 Esse valor não inclui os honorários médicos nem os custos de internação do paciente (hotelaria).

16 Micromolas, fio guia hidrofílica, cabo destacador, introdutor prelude, micro cateter, balão de oclusão e selador hemostático.

17 Os convênios acordam com os hospitais o pagamento de um valor específico para determinado procedimento. Se houver complicação, o material e procedimentos subsequentes são de responsabilidade do hospital.

$18 \mathrm{Na}$ prática, as mensalidades variam anualmente.

19 As empresas de seguros-saúde realizam cálculos atuariais para verificar o risco e fixar os preços de acordo com probabilidades de sinistralidade. O cumprimento da meta atuarial é uma condição a ser perseguida pela empresa de seguro-saúde.

20 Através das glosas, a operadora pode decidir o volume de recursos que deverão ser pagos, mensalmente, aos prestadores. A prática do mercado é que despesas encaminhadas até o dia 15 são pagas no dia 30, e as encaminhadas entre os dias 15 e 30 são pagas no dia 15 do mês subsequente. Assim, a palavra controle deve ser vista sob o ponto de vista da adequação do fluxo de caixa. Outras formas de controle são a autorização prévia para realização de procedimentos de alta complexidade e a aquisição de material pela operadora para cirurgias, em que a operadora cota preços e compra material mais barato.

21 Uma análise que pode ser intensificada aqui é a portabilidade. A permissão de migração de indivíduos entre operadoras pode alterar a composição dessa distribuição mercadológica e levar algumas empresas a deixar o mercado. As regras da portabilidade foram definidas, mas sua aplicabilidade ainda requer diversos ajustes. 
22 Note-se que, independente da relação entre $\alpha$ e $\beta$, as conotações econômicas são perceptíveis em cada um dos cenários acima apresentados. Note-se, ainda, que variáveis como emprego ou renda podem ser usadas para dimensionar melhor o mercado de saúde suplementar em qualquer economia.

23 Goldberg apud Gujarati (2006, p. 287) mostra que a micronumerosidade cria problemas iguais àqueles gerados pela multicolinearidade.

24 Para não correr risco de perder o seguro-saúde, o usuário pode optar por um plano mais barato, ou seja, fazer uso da portabilidade.

\section{Referências}

AGÊNCIA NACIONAL DE SAÚDE (ANS). Informações de saúde suplementar. 2010a. Disponível em: <www.ans.gov.br/perfil-dosetor/dados-e-indicadores-do-setor $>$. Acesso em: 2 ago. 2010.

AGÊNCIA NACIONAL DE SAÚDE (ANS). Caderno de Informação de Saúde Suplementar, 2010. 2010b. Disponível em: <www.ans.gov. br/perfil-do-setor/dados-e- indicadores-dosetor>. Acesso em: 3 fev. 2011.

ANDRADE, Mônica V.; LISBOA, Marcos. Determinantes dos gastos pessoais privados com saúde no Brasil. Texto para discussão, 175. Belo Horizonte: Cedeplar/Face/UFMG, 2002. 24p.

ARROW, Kenneth. Uncertainty and the welfare economics of medical care. American Economic Review, n. 53, p. 941-973, dez. 1963.

BAHIA, Lígia. O mercado de planos e seguros de saúde no Brasil: tendências pós-regulamentação. In: NEGRI, Barjas; GIOVANNI, Geraldo di (org.). Brasil: radiografia da saúde. Campinas: Unicamp, IE, 2001. p. 325-361.

BAHIA, Lígia. Padrões e mudanças no financiamento e regulação do sistema de saúde brasileiro: impactos sobre as relações entre o público e privado. Saúde e Sociedade, São Paulo, v. 14, n. 2, p. 9-30, 2005.

BARROS, Maria E.; PIOLA, Sérgio F.; VIANNA, Solon M. Política de saúde no Brasil: diagnóstico e perspectiva. Brasília, DF: IPEA, 1995.

BRAGA, Márcio B.; KANNEBLEY- JÚNIOR, Sérgio; ORELLANO, Veronica I. F. Matemática para economistas. São Paulo: Atlas, 2003.

BECKER, Gary. Investiment in human capital: a theorical analisys. The Journal of Political Economy, [s.l.], v. 70, n. 5, p. 9-49, Oct. 1962.

BRASIL. Constituição. República Federativa do Brasil. Promulgada em 5 de outubro de 1988. 16. ed. São Paulo: Editora Saraiva, 1997.

BRASIL. Presidência da República. Lei n. 8.080/90, de 19 de setembro de 1990. Dispõe sobre as condições para a promoção, proteção e recuperação da saúde, a organização e o funcionamento dos serviços correspondentes e dá outras providências. Disponível em: $<$ www.planalto.gov.br/ccivil_03/leis/L8080. htm>. Acesso em: 19 fev. 2010. 
BRASIL. Ministério do Planejamento, Orçamento e Gestão. Secretaria de Orçamento Federal. Resultado primário da seguridade social, 2010. 2010. Disponível em: <http:// antigo.planejamento.gov.br/ministerio.asp? index $=8 \&$ ler $=$ t9716> . Acesso em: 13 jan. 2011.

CONSELHO FEDERAL DE MEDICINA (CFM). Resolução CMF n. 1.805/2006. Diário Oficial da União, Seção I, p. 169, Brasília, DF, 2006.

CORDEIRO, Hésio. A indústria de saúde no Brasil. Rio de Janeiro: Graal, 1980.

DAIN, Sulamis; JANOWITZER, Rejane. A saúde complementar no contexto dos sistemas de saúde: a experiência internacional. In: BIASOTO-JÚNIOR, Geraldo (org.). Série técnica: desenvolvimento de sistemas de saúde. Brasília: Organização Pan-Americana de Saúde, 2006. p. 17-70.

FOLLAND, Sherman; GOODMAN, Allen C.; STANO, Miron. A economia da saúde. 5. ed. Porto Alegre: Bookman, 2008.

FREITAS, Maurício A. L. Viabilidade econômica e eficiência do sistema de saúde: o caso do polo médico da cidade do Recife. 116 fls. Dissertação (Mestrado em Economia) - Programa de Pós-Graduação em Economia, Universidade Federal de Pernambuco, Recife, 2002.

FREITAS, Maurício A. L. Crescimento econômico ótimo: a influência do sistema de saúde. 142 fls. Tese (Doutorado em Economia) Programa de Pós-Graduação em Economia, Universidade Federal de Pernambuco, Recife, 2009.

GOLDBERG, Arthur S. Topics in Regression Analisys, American Journal of Sociology, v. 77, n. 1, p. 158-160, jul. 1971 .

GUJARATI, Damodar N. Econometria básica. Rio de Janeiro: Elsevier, 2006. 801p.

HENDERSON, James M.; QUANDT, Richard. Teoria microeconômica: uma abordagem matemática. 3. ed. São Paulo: Livraria Pioneira Editora, 1992.
HOWITT, Peter. Health, human capital and economic growth: a Schumpeterian perspective. Brown University. 2005. Disponível em: $<$ www.econ.brown.edu/fac/Peter_Howitt/ publication/PAHO.pdf $>$. Acesso em: 25 jul. 2008.

INSTITUTO BRASILEIRO DE GEOGRAFIA E ESTATÍSTICA. Pesquisa de Assistência Médico-Sanitária (IBGE-AMS). 2009. Disponível em: <www.ibge.gov.br/home/estatistica/ populacao/condicaodevida/ams/2009>. Acesso em: 12 jul. 2010.

LIMA, Clóvis R. M. Informação, assimetria de informações no mercado de saúde suplementar. Encontros Bibli, Florianópolis, v. 11, n. 22, p. 132-146, 2006.

MARINHO, Alexandre. Estudo de eficiência de hospitais públicos e privados com geração de rankings. Revista de Administração Pública, Rio de Janeiro, v. 32, n. 6, p. 145-158, 1998.

MANFREDINI, Marco A.; BOTAZZO, Carlos. Tendências da indústria de equipamentos odontológicos no Brasil entre 1990 e 2002 : notas prévias. Ciência \& Saúde Coletiva, Rio de Janeiro, v. 11, n. 1, p. 169-177, 2006.

MANKIW, Nicholas G.; ROMER, David; WEIL, David N. A Contribution to the Empirics of Economic Growth. Quarterly Journal of Economics, v. 107, n. 2, p. 407-437, 1992.

MANSUR, Marília C. O financiamento federal da saúde no Brasil: tendências da década de 1990. Dissertação (Mestrado em Saúde Pública) - Escola Nacional de Saúde Pública Sergio Arouca, Fundação Oswaldo Cruz, Rio de Janeiro, 2001.

PINDICK, Robert. S; RUBINFELD, Daniel. L. Microeconomia. Campus. São Paulo, 2006.

PIERONI, João P.; REIS, Carla; SOUZA, José O. B. A indústria de equipamentos e materiais médicos, hospitalares e odontológicos: uma proposta de atuação do BNDES. Ministério do Desenvolvimento, Indústria e Comércio Exterior. BNDES Setorial, Brasília, n. 31, p. 185-226, 2010. 
PIOLA, Sérgio F.; BIASOTO-JÚNIOR, Geraldo. Financiamento do SUS nos anos 90. In: NEGRI, Barjas; GIOVANNI, Geraldo (org.). Brasil: radiografia da saúde. Campinas: Unicamp, IE, 2011. p. 219-232.

PIOLA, Sérgio F.; VIANNA, Solon. Economia da saúde: conceito e contribuição para a gestão da saúde. Brasília: IPEA, 1995.

PROFUTURO. Programa de Estudos do Futuro. A saúde no Brasil e na América Latina. São Paulo: FEA/USP, 2008.

TRIBUNAL SUPERIOR DE JUSTIÇA (TSJ). Relatório 668.216. Ministro Carlos Alberto Menezes Direito. 29 jun. 2007. Disponível em: <www.tsj.gov.br/SCON/jurisprudencia/ toc.jsp?tipo_visualizacao $=$ RESUMO\&livre $=$ $668216 \& \& b=$ ACORD $\& \mathrm{p}=\operatorname{true} \& \mathrm{t}=\& \mathrm{l}=$ $10 \& \mathrm{i}=61>$. Acesso em: 10 ago. 2010.
UGÁ, Maria A. D. et al. Descentralização e alocação de recursos no âmbito do Sistema Único de Saúde (SUS). Ciência \& Saúde Coletiva, Rio de Janeiro, v. 8, n. 2, p. 417-437, 2003.

UGÁ, Maria A. D.; SANTOS, Isabela S. Uma análise da equidade do financiamento do sistema de saúde brasileiro: relatório do projeto "Justiça no Financiamento do Setor de Saúde". Rio de Janeiro: Escola Nacional de Saúde Pública, Fiocruz, 2005.

ZUCCHI, Paola; BITTAR, Olímpio J. N. V.; HADDAD, Nagib. Produtividade em hospitais de ensino de acordo com indicadores hospitalares. Revista Panamericana de Salud Pública, Washington, v. 4, n. 5, p. 311-316, 1998.

Recebido em 02/07/2013

Aprovado em 08/04/2014 